DIW BERLIN

Discussion

Papers

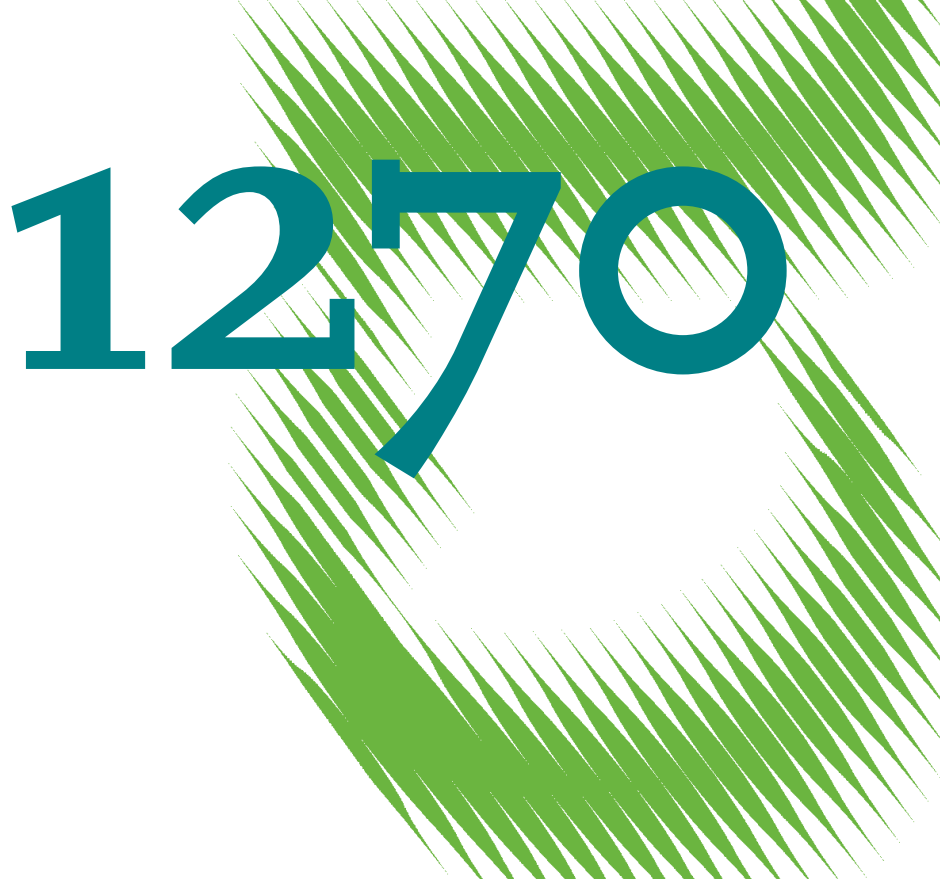

The Spatial Dimension of

US House Price Developments 
Opinions expressed in this paper are those of the author(s) and do not necessarily reflect views of the institute.

IMPRESSUM

(C) DIW Berlin, 2013

DIW Berlin

German Institute for Economic Research

Mohrenstr. 58

10117 Berlin

Tel. $+49(30) 89789-0$

Fax +49 (30) $89789-200$

http://www.diw.de

ISSN print edition $1433-0210$

ISSN electronic edition 1619-4535

Papers can be downloaded free of charge from the DIW Berlin website:

http://www.diw.de/discussionpapers

Discussion Papers of DIW Berlin are indexed in RePEc and SSRN:

http://ideas.repec.org/s/diw/diwwpp.html

http://www.ssrn.com/link/DIW-Berlin-German-Inst-Econ-Res.html 


\title{
The Spatial Dimension of US House Price Developments
}

\author{
Katharina Pijnenburg* \\ DIW Berlin
}

\begin{abstract}
February 13, 2013

Spatial heterogeneity and spatial dependence are two well established aspects of house price developments. However, the analysis of differences in spatial dependence across time and space has not gained much attention yet. In this paper we jointly analyze these three aspects of spatial data. We apply a panel smooth transition regression model that allows for heterogeneity across time and space in spatial house price spillovers and for heterogeneity in the effect of the fundamentals on house price dynamics.

We find evidence for heterogeneity in spatial spillovers of house price developments across space and time: house price developments in neighboring regions spill over stronger in times of increasing neighboring house prices compared to declining neighboring house prices. This is interpreted as evidence for the disposition effect. Moreover, heterogeneity in the effect of the fundamentals on house price dynamics could not be detected for all variables; real per capita disposable income and the unemployment rate have a homogeneous effect across time and space.
\end{abstract}

Keywords: Heterogeneity in Spatial Dependence, Panel Smooth Transition Regression, Housing Prices, Disposition Effect

JEL Classification: C23, R12, R31

\footnotetext{
*This paper represents the author's personal opinions and does not necessarily reflect the views of DIW Berlin. Contact: German Institute for Economic Research, Mohrenstraße 58, 10117 Berlin, Germany, Phone: +49 30 89789-589, E-mail: kpijnenburg@diw.de
} 


\section{Introduction}

When analyzing regional house price data, the two specific spatial aspects of regional data, namely spatial dependence and spatial heterogeneity (Anselin, 1988), need to be taken into account. This becomes clear when examining two time periods of annual house price growth rates in US metropolitan statistical areas (MSAs) plotted in Figure 1. The strong annual house price growth rates observed in California in 2004 are apparently transmitted to the northern coastal regions, as higher rates can be observed in those regions in 2005. This transmission of house price developments across space is what is called spatial dependence. Furthermore, the two maps suggest that house price dynamics in coastal regions are different from house price developments in the inland. This difference in the dynamics is called spatial heterogeneity. Moreover, as the house price spillovers appear to be stronger along the coastal regions it could be the case that there are differences in spatial house price spillovers across space and possibly across time, i.e. that there is heterogeneity in spatial dependence. In our analysis of regional house price developments in the US we jointly analyze these three aspects of spatial data, namely spatial dependence, spatial heterogeneity and heterogeneity in spatial dependence.

Spatial dependence and spatial heterogeneity are two well established aspects of house price developments. However, differences in spatial spillovers across space and time have not gained much attention yet. A possible explanation of those differences in spillovers could be the so-called disposition effect (Shefrin and Statman, 1985). The disposition effect labels the phenomenon in financial markets that investors sell their winning stocks too soon and hold their losing stocks too long. Applied to the real estate market this would mean that homeowners hold their houses even if they get strong signals of declining house prices. The disposition effect implies reduced house price spillovers in times of declining house prices. Assuming incorrectly homogeneous spillovers across space and time could locally give a misleading picture of house price dynamics.

We use a panel smooth transition regression model which allows us to jointly analyze these three aspects of spatial data. González et al. (2005) develop this model in order to describe heterogeneous panels, where the coefficients can vary between regions and with time. Spatial dependence is introduced by including the spatial lag of house price developments, spatial heterogeneity is introduced by allowing the 
fundamentals to have heterogeneous effects across time and space, and heterogeneity in house price spillovers is introduced by allowing the spatial dependence parameter to change over time and with space. To the best of our knowledge this is the first paper providing a joint analysis of all three spatial aspects, the first paper that explicitly models heterogeneity across time and space in spatial dependence, and the first paper which tries to model the disposition effect using heterogeneity in spatial spillovers.

The results reveal that house price developments in neighboring regions spill over more in times of increasing neighboring house prices than during times of declining neighboring house prices. This is seen as evidence for the disposition effect. Heterogeneity in the effect of the fundamentals on house price dynamics is only found for population growth and building permits, but not for real per capita disposable income and the unemployment rate. The detected heterogeneity in the effect of population growth on house price developments suggest that fundamentals serve less explaining the house price developments in times of declining house prices compared to strongly increasing house prices.

The paper is organized as follow. In section two we explain in more detail the theory and the empirical evidence of the three spatial aspects. In section three we present the econometric approach. Section four describes the available data. In section five we provide and discuss the empirical results, while section six concludes.

\section{Theoretical Aspects and Empirical Evidence}

Spatial dependence in house price developments is also known as the ripple effect. Accordingly, house price developments in one region cause house price movements in neighboring regions (Giussani and Hadjimatheou, 1991; Meen, 1999). Migration, equity transfer, information asymmetries and the spatial patterns in the fundamentals of house prices play a key role in the spatial spillovers of house prices (Meen, 1999). Migration or equity transfer to regions where house prices are comparably low could lead to the ripple effect by increasing demand and thereby prices. Information asymmetries may imply that new information regarding the housing market available in one area are transmitted only gradually to other sub-markets. Finally, the ripple effect could appear if variables explaining house price developments show 
Figure 1: Annual growth rate of regional house prices, US metropolitan statistical areas

\section{Q2}

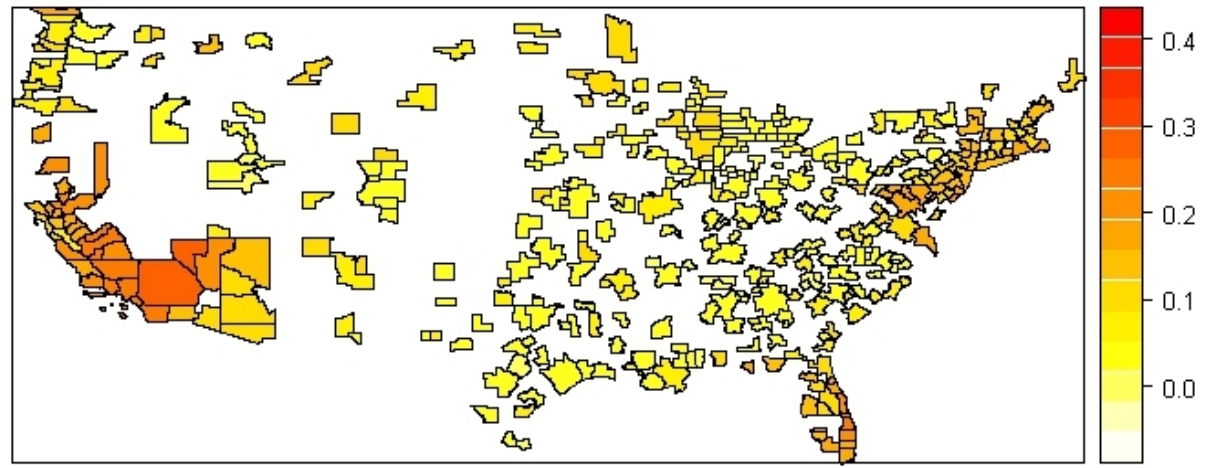

2005 Q2

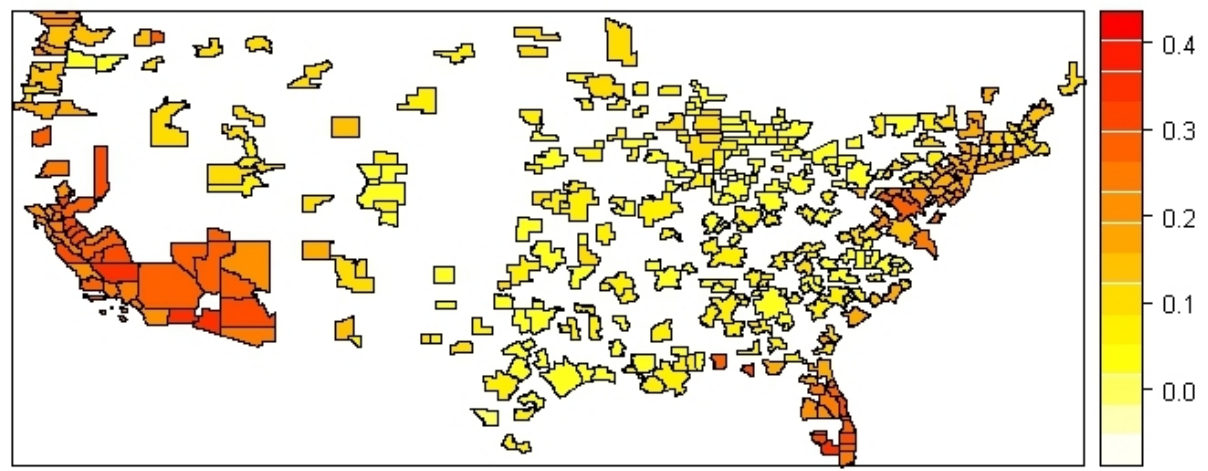


themselves a spatial pattern.

Empirical evidence regarding spatial spillovers of house price developments is quite strong. Kuethe and Pede (2011) find in their analysis of house prices in Western United States that instate housing price forecasts can be improved by using housing prices in neighboring states. Furthermore, their results indicate that previous house prices in space and time impact current house prices. Similarly, Holly et al. (2011) find dynamic spillover effects of house prices from the neighboring regions. The diffusion of regional house prices in California counties across space is found to last up to two and a half years (Brady (2011)).

But, housing markets exhibit not only spatial dependence but also spatial heterogeneity. Following Wood (2003), one reason for spatial heterogeneity could be that some regions respond more rapidly to national economic shocks than others because their housing market is more liquid and new information is reflected more quickly in the house prices. Meen (1999) argues that heterogeneity arises because of different household behavior and household composition. Moreover, the supply of housing could be limited by planning constraints or by geographical constraints like mountains or lakes. Thus, house prices react differently to changes in demand conditions if supply cannot adjust.

Empirical evidence for spatial heterogeneity is found by van Dijk et al. (2011), who detect the existence of two clusters of regions in the Netherlands. Regions within the cluster have the same house price dynamics, while the dynamics are different across clusters. The different clusters can be distinguished among others by the average growth rate of house prices. Furthermore, Dieleman et al. (2000) detect three clusters in their analysis of 27 metropolitan housing markets in the US, where the clusters where chosen based on the average median price and rent level. The authors find that house prices are geographical autocorrelated within the cluster.

Heterogeneity in house price spillovers over time is analyzed by de Bandt and Malik (2010) and de Bandt et al. (2010). The authors find stronger spillovers in crises times compares to normal times. A possible explanation of those differences in spillovers across time could be the so-called disposition effect (Shefrin and Statman, 1985). The disposition effect labels the phenomenon in financial markets that investors sell their winning stocks too soon and hold their losing stocks too long. Applied to the real estate market this would mean that homeowners hold their houses even if they get strong signals of declining house prices.

The prospect theory (Kahneman and Tversky, 1979), mental accounting (Thaler, 
1999), and cognitive dissonance (Festinger, 1957) are concepts that may explain such behavior.

According to the prospect theory, individuals follow an S-shaped value function. Starting from a reference point, this function is concave downward above this reference point and concave upward below this reference point. This implies that individuals are risk-seeking for wealth levels below the reference point. Thus, they hold on their asset too long and, thereby take bigger risks. Genesove and Mayer (2001) find that sellers in the housing market are averse to realizing nominal losses as predicted by the prospect theory. The same is found by Engelhardt (2003).

The concept of mental accounting means that individuals group elements of their consumption and expenditures in mental accounts. They follow their personal rules in managing those accounts and react in different ways to the investments in the different accounts. When homeowners hold on their losing asset, it is because in their mental account the loss is only booked when the asset is sold and this may explain the disposition effect.

Finally, "cognitive dissonance is the mental conflict that people experience when they are presented with evidence that their beliefs or assumptions are wrong" (Shiller, 1999, p. 1314). People experiencing cognitive dissonance try to trivialize or avoid the new information, developing explanations as to why their current beliefs or assumptions should not be revised. For the housing market this would mean that homeowners avoid the information of declining house prices in neighboring regions or try to find explanations as to why this decline only applies to the neighboring region.

In sum, the disposition effect implies reduced spatial spillovers in times of declining house prices.

However, in a spatial setting the disposition effect may not only explain heterogeneity in spatial spillovers across time but also across space. This is the case as the relevant signals regarding house price developments in a given region are likely to come from neighboring regions. If house prices in neighboring regions decline, the spatial spillover is expected to be smaller compared to spillovers in regions, where house prices still increase. This implies different house price spillovers at a given moment in time because of heterogeneous house price developments across regions within the country.

In addition, heterogeneity in spatial dependence across space could arise because of different migration patterns. Kosfeld (2006), for example, finds differences in labor mobility between East and West Germany, and Molloy et al. (2011) find differences 
in labor mobility across US regions. Furthermore, differences in the liquidity of the housing market and, thereby, in the transmission of price information and search costs could result in different amounts of information asymmetries across regions. Kodres and Pritsker (2002) find, in their model analyzing financial contagion, that information asymmetries may lead to stronger spillovers of financial shocks. They explain that due to information asymmetries shocks hitting only neighboring regions are mistakenly seen as shocks also hitting the region under consideration. de Bandt and Malik (2010) argue that even if housing markets are different from financial markets, financial contagion could also occur in the housing market. Thus, information asymmetries could result in heterogeneity of spatial house price spillovers across space. To our knowledge, the only paper analyzing heterogeneity in house price spillovers across space is Gray (2012). In his analysis of house price movements in England and Wales, the author finds differences in house price spillovers across space.

\section{Econometric Approach}

In the first step, we simply estimate a spatial panel fixed effects regression. This allows us to get an idea of the overall spatial spillover effect of house price developments. In a second step, the panel smooth transition regression model is estimated in order to capture the heterogeneity in spatial dependence across time and space as well as the heterogeneity in the effect of the fundamentals. ${ }^{1}$

\subsection{Spatial Fixed Effects Panel Estimation}

Including a spatial lag of the dependent variable in our panel estimation allows us to capture the spatial spillovers of house price developments of the neighboring regions. Which regions are defined as neighbors is determined by the spatial weight matrix $W_{N}$, of dimension $N \times N$ (Anselin et al., 2008). Each element of the weight matrix, $w_{\mathrm{ij}}$, determines the strength of the interaction between regions $i$ and $j$. If there is no interaction between region $i$ and $j, w_{\mathrm{ij}}$ is equal to zero. By convention, the diagonal elements, $w_{\mathrm{ii}}$, are equal to zero. In our estimation the weights are equal to the inverse distance, $\frac{1}{d_{\mathrm{ij}}}$, where $d_{\mathrm{ij}}$ is the distance between region $i$ and $j$.

\footnotetext{
${ }^{1}$ Smooth transition autoregressive models were first used in time series analysis to model nonlinearity and asymmetric response (Terasvirta, 1994).
} 
All regions within a distance of $330 \mathrm{~km}$ are going to have a positive weight in the spatial weight matrix. This distance is the smallest possible, where all regions have at least one neighbor. Furthermore, the weights are row standardized, which means that the elements of each row sum up to one. This transformation implies that $W_{N}$ is no longer symmetric. For the panel case, the cross-sectional weight matrix $W_{N}$ is stacked t times. Thus, we assume that the spatial weight matrix does not change over time.

$$
W_{\mathrm{NT}}=I_{T} \otimes W_{N}
$$

The vector of spatially lagged dependent variables is written as:

$$
\mathrm{Wy}=W_{\mathrm{NT}} y=\left(I_{T} \otimes W_{N}\right) y \text {. }
$$

As mentioned above, regions are hit by house price development of neighboring regions with a certain time lag. Following the Akaike information criteria we include the spatially lagged dependent variable lagged by one period. Anselin et al. (2008) call this a pure space recursive model. Pure space recursive models can simply be estimated by ordinary least squares (OLS) (Lee and Yu, 2010). The general notation of the fixed effects spatial lag model we are going to estimate is:

$$
y_{\mathrm{t}}=\rho\left(I_{T} \otimes W_{N}\right) y_{\mathrm{t}-1}+\left(\iota_{t} \otimes \mu\right)+\mathrm{X} \beta+\nu_{\mathrm{t}},
$$

where $y$ is the dependent variable, $\rho$ the spatial dependence parameter, and $\mu$ the region specific fixed effect. In our spatial fixed effects panel estimation, the dependent variable, real quarterly house price growth rate, $h p i$, is regressed on annual population growth, population; annual growth of the unemployment rate, unemployment; annual growth of real per capita disposable income, income; the log of building permits per population, building permits; the spatial lag of the dependent variable, Whpi; and on quarterly time dummies (Equation 4). We include time dummies to capture changes in the fundamentals that hit all regions at the same time, like for example changes in the federal funds rate. Furthermore, we estimate a fixed effects regression to capture all time invariant region specific effects, $\mu_{i}$. The different lags 
of the explanatory variables are chosen based on the Akaike information criteria. ${ }^{2}$

$$
\begin{aligned}
\mathrm{hpi}_{\mathrm{it}}= & \mu_{i}+\alpha \text { population }_{\mathrm{it}-3}+\beta \text { unemployment }_{\mathrm{it}-2}+\zeta \text { income }_{\mathrm{it}-2} \\
& +\delta \text { building permits } \\
\mathrm{it}-1 & +\rho \sum_{j=1}^{N} w_{\mathrm{ij}} \mathrm{hpi}_{\mathrm{jt}-1}+\nu_{\mathrm{it}} .
\end{aligned}
$$

The results of this estimation give an idea of the overall spatial dependence in house price dynamics and of the effect of the fundamentals, disregarding any heterogeneity across space or time.

\subsection{Fixed Effects Panel Smooth Transition Regression Model}

To include heterogeneity in the model, a non-dynamic fixed effects panel smooth transition regression model (PSTR) is estimated (González et al., 2005). This model allows the coefficients of the explanatory variables to vary between regions and with time. The coefficients change smoothly as a function of the transition variable and are, thereby, a continuous function of this transition variable. This model appears to be especially appropriate for our setting, as it allows the spatial dependence coefficient and the coefficients of the fundamentals to vary across space and time. Thereby, spatial heterogeneity in house price developments is modeled by the changing coefficients of the fundamentals; heterogeneity in house price spillovers is modeled by the changing spatial dependence coefficient. Following González et al. (2005), the PSTR model is written as follows:

$$
y_{\mathrm{it}}=\mu_{i}+\theta_{0}^{\prime} x_{\mathrm{it}}+\theta_{1}^{\prime} x_{\mathrm{it}} g\left(q_{\mathrm{it}} ; \gamma, c\right)+\nu_{\mathrm{it}}
$$

where $g\left(q_{\text {it }} ; \gamma, c\right)$ is the transition function, which is normalized to be bounded between zero and one. When the transition function is equal to zero, the coefficient of a given explanatory variable is $\theta_{0}$; when the transition function is equal to one, the coefficient is $\theta_{0}+\theta_{1}$. The transition variable is $q_{i t}$. González et al. (2005) develop the PSTR model for the logistic specification of the transition function. For the case of two extreme regimes, the logistic transition function is given by:

$$
g\left(q_{\mathrm{it}} ; \gamma, c\right)=\frac{1}{1+e^{-\gamma\left(q_{\mathrm{it}}-c\right)}},
$$

\footnotetext{
${ }^{2}$ The results barely change when different lag specifications are used.
} 
where $c$ is the location parameter, and $\gamma$ is the slope of the transition function that determines the smoothness of the transition between two regimes. The higher $\gamma$, the faster is the transition between two regimes. For $\gamma$ going to infinity the transition is instantaneous. For $\gamma$ going to zero, the transition function becomes constant and this implies that there are no regimes at all. If the transition variable, $q_{\mathrm{it}}$, is smaller than the location parameter, $c$, the transition function, $g\left(q_{\mathrm{it}} ; \gamma, c\right)$, tends to zero, and the coefficients tend to $\theta_{0}$. If the transition variable, $q_{i t}$, is larger than the location parameter, $c$, the transition function, $g\left(q_{\text {it }} ; \gamma, c\right)$, tends to one, and the coefficients tend to $\theta_{0}+\theta_{1}$.

In the empirical application, the transition variable should capture the source of the parameter heterogeneity. A good candidate for the transition variable in our analysis is the spatially weighted house price development of the neighboring regions, Whpiag ${ }_{t-1}$, (Figure 2). There are several reasons for this choice: First,

Figure 2: Transition variable - spatially weighted annual real house price growth rate of neighboring regions, Whpiagt-1

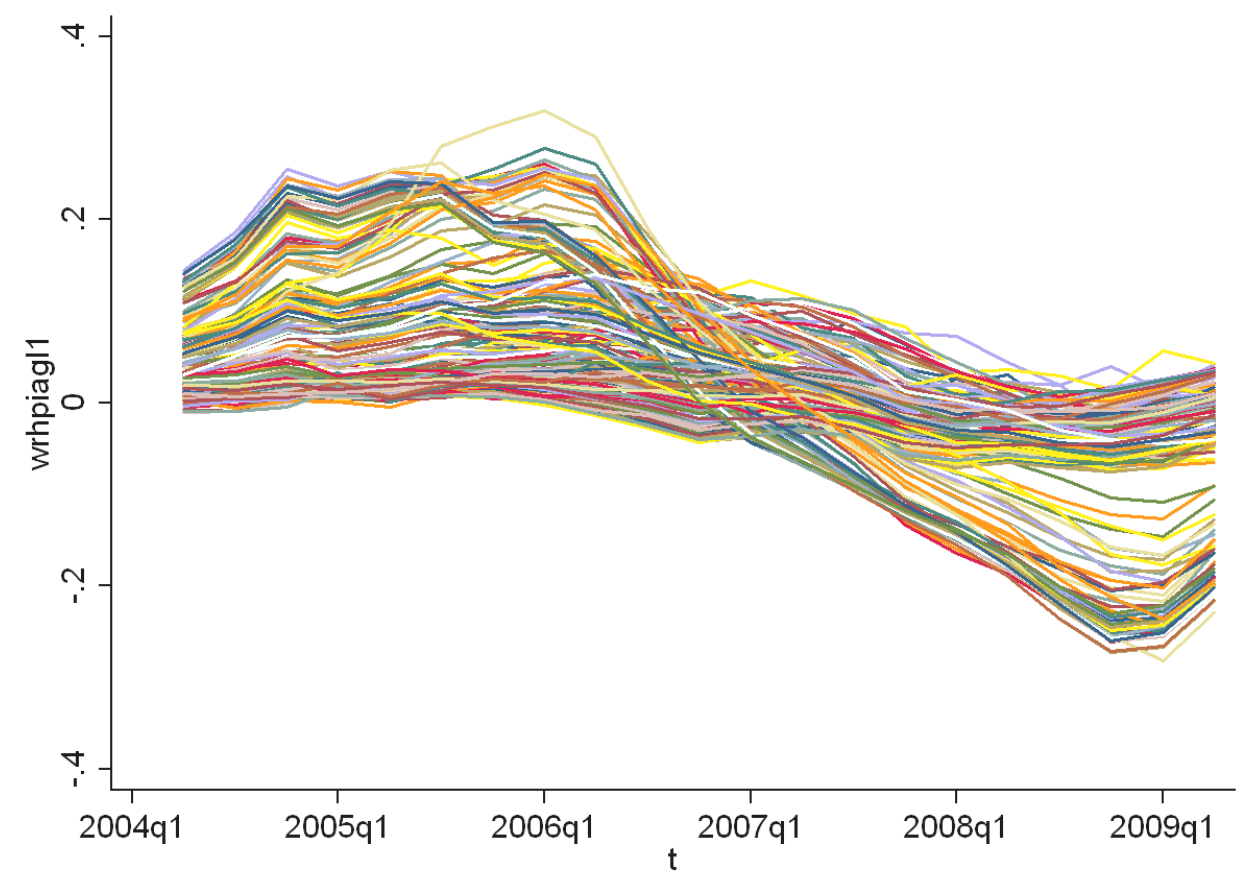

de Bandt and Malik (2010) and de Bandt et al. (2010) find stronger spillovers in crises times when compared to normal times. Normal times in the housing market could be expressed by relatively normal average house price developments, while crisis times would be expressed by extreme increases or decreases in housing prices. 
Taking spatially weighted neighboring house price developments should be a good approximation for the overall house price development in the larger geographical region where an MSA is located.

Second, this variable seems to be a good candidate for the transition variable, as Dieleman et al. (2000) and van Dijk et al. (2011) find different house price developments within clusters, where the clusters are defined by average house price growth rates. Again, neighboring house price developments should be a good approximation of the average house price development in the larger geographical region where an MSA is located.

Third, the disposition effect for the housing market implies that a region does not react as strongly to signals of declining house prices as to signals of increasing house prices. It is reasonable to assume that those signals come from neighboring regions. Therefore, the transition variable formed by the spatially weighted house price development of the neighboring regions should be able to model the disposition effect in the housing market. In this respect, the logistic specification of the PSTR model, compared to an exponential specification, is appropriate for our setting as we expect different spillovers depending on whether we are above or below the location parameter, $c$. This consideration together with the fact that the estimation is conducted over a relative short time span of 21 quarters, it is reasonable to assume that there are only two extreme regimes.

In sum, the transition variable allows us to capture heterogeneity in spatial house price spillovers and heterogeneity in the effect of the fundamentals on house price developments. However we are aware that this transition variable does not capture heterogeneity in spatial spillovers due to different migration patterns or different amounts of information asymmetries.

For estimating the parameters $\theta_{0}^{\prime}, \theta_{1}^{\prime}, \gamma$, and $c$, in a first step the region specific means need to be removed to eliminate the region specific effects, $\mu_{i}$. The model can then be written as:

$$
\tilde{y}_{\mathrm{it}}=\theta^{\prime} \tilde{x}_{\mathrm{it}}(\gamma, c)+\tilde{\nu}_{\mathrm{it}},
$$

where $\tilde{y}_{\mathrm{it}}=y_{\mathrm{it}}-\bar{y}_{\mathrm{it}} ; \tilde{x}_{\mathrm{it}}(\gamma, c)=\left(x_{\mathrm{it}}^{\prime}-\bar{x}_{i}^{\prime}, x_{\mathrm{it}}^{\prime} g\left(q_{\mathrm{it}} ; \gamma, c\right)-\bar{z}_{i}^{\prime}(\gamma, c)\right)^{\prime}$ and $\bar{z}_{i}(\gamma, c)=$ $\frac{1}{T} \sum_{t=1}^{T} x_{\mathrm{it}} g\left(q_{\mathrm{it}} ; \gamma, c\right)$. This model is linear in $\theta$ given $\gamma$ and $c$. However, the matrix of transformed explanatory variables, $\tilde{X}_{\text {it }}(\gamma, c)$, depends on $c$ and $\gamma$ and thereby needs to be recomputed at each iteration in the nonlinear least squares (NLS) estimation. 
$c$ and $\gamma$ are determined by applying NLS to the concentrated sum of squared errors:

$$
Q^{c}(\gamma, c)=\sum_{i=1}^{N} \sum_{t=1}^{T}\left(\tilde{y}_{\mathrm{it}}-\hat{\theta}(\gamma, c) \tilde{x}_{\mathrm{it}}(\gamma, c)\right)^{2},
$$

where $\hat{\theta}(\gamma, c)$ is obtained from OLS of equation 7 .

The corresponding PSTR model for our estimation of US regional house price dynamics is written as:

$$
\begin{aligned}
\text { hpi }_{\mathrm{it}}= & \mu_{i}+\alpha_{0} \text { population }_{\mathrm{it}-3}+\beta_{0} \text { unemployment }_{\mathrm{it}-2}+\zeta_{0} \text { income }_{\mathrm{it}-2} \\
& +\delta_{0} \text { building permits }_{\mathrm{it}-1}+\rho_{0} \sum_{j=1}^{N} w_{\mathrm{ij}} \mathrm{hpi}_{\mathrm{jt}-1} \\
& +\left[\alpha_{1} \text { population }_{\mathrm{it}-3}+\beta_{1} \text { unemployment }_{\mathrm{it}-2}+\zeta_{1} \text { income }_{\mathrm{it}-2}\right. \\
& \left.+\delta_{1} \text { building permits }_{\mathrm{it}-1}+\rho_{1} \sum_{j=1}^{N} w_{\mathrm{ij}} \mathrm{hpi}_{\mathrm{jt}-1}\right] g\left(\text { Whpiag }_{\mathrm{it}-1} ; \gamma, c\right) \\
& +\nu_{\mathrm{it}} .
\end{aligned}
$$

Later on we will use the notation $\Theta_{p}=\left(\alpha_{p} \beta_{p} \zeta_{p} \delta_{p} \rho_{p}\right)$ for $p=(0,1)$. If we assume two extreme regimes, the transition function, $g\left(W\right.$ hpiag $\left._{\text {it }-1} ; \gamma, c\right)$, will tend to one for high values of the transition variable, $W$ hpiag $_{\text {it-1 }}$. This implies that whenever we observe high neighboring house price growth rates, the spatial spillover parameter will tend to $\rho_{0}+\rho_{1}$, and correspondingly the other explanatory variables. Whenever we observe low or decreasing neighboring house price growth rates, the spatial spillover parameter will tend to $\rho_{0}$, and correspondingly the other explanatory variables. In the estimation we expect $\rho_{0}$ to be smaller than $\rho_{0}+\rho_{1}$, as the disposition effect predicts smaller house price spillovers in times of declining house prices. ${ }^{3}$

\section{Data description}

We use data for 319 metropolitan statistical areas. Out of the existing 366 MSAs in 2012, we chose this sample due to data availability issues. Figure 4 plots the 319 MSAs used in the estimation. Following the United States Census Bureau, "the general concept of a metropolitan area is that of a large population nucleus, together

\footnotetext{
${ }^{3}$ The estimations are performed in Matlab (R2009a). We would like to thank Christophe Hurlin for kindly providing his STAR-Panel code.
} 
with adjacent communities having a high degree of social and economic integration with that core" (Federal Register, 2010, p. 37246).

Table 1: Data description

\begin{tabular}{|c|c|c|c|}
\hline Variable & Description & Time span & Source \\
\hline House price index & $\begin{array}{l}\text { House prices, all } \\
\text { transactions } \\
\text { index }\end{array}$ & $\begin{array}{l}\text { quarterly, } \\
\text { 1986Q4-2010Q4 }\end{array}$ & $\begin{array}{l}\text { Federal Housing Finance } \\
\text { Agency }\end{array}$ \\
\hline $\begin{array}{l}\text { Nominal per } \\
\text { capita disposable } \\
\text { income }\end{array}$ & & $\begin{array}{l}\text { annually, } \\
1977-2009\end{array}$ & $\begin{array}{l}\text { Bureau of Economic } \\
\text { Analysis }\end{array}$ \\
\hline Population & & $\begin{array}{l}\text { annually, } \\
1977-2009\end{array}$ & $\begin{array}{l}\text { Bureau of Economic } \\
\text { Analysis }\end{array}$ \\
\hline $\begin{array}{l}\text { Consumer price } \\
\text { index }\end{array}$ & $\begin{array}{l}\text { Consumer price } \\
\text { index (all urban } \\
\text { consumers) }\end{array}$ & $\begin{array}{l}\text { annually, } \\
1984-2010\end{array}$ & $\begin{array}{l}\text { Bureau of Labor } \\
\text { Statistics }\end{array}$ \\
\hline $\begin{array}{l}\text { Unemployment } \\
\text { rate }\end{array}$ & & $\begin{array}{l}\text { monthly, } \\
\text { 1990M1-2011M3 }\end{array}$ & $\begin{array}{l}\text { Bureau of Labor } \\
\text { Statistics }\end{array}$ \\
\hline Land area & $\begin{array}{l}\text { Tiger/Line } \\
\text { shapefile }\end{array}$ & & $\begin{array}{l}\text { United States Census } \\
\text { Bureau }\end{array}$ \\
\hline Building permits & $\begin{array}{l}\text { New privately } \\
\text { owned housing } \\
\text { units }\end{array}$ & $\begin{array}{l}\text { monthly, } \\
\text { 2004M1-2012M9 }\end{array}$ & $\begin{array}{l}\text { United States Census } \\
\text { Bureau }\end{array}$ \\
\hline
\end{tabular}

For the dependent variable, house prices, the Federal Housing Finance Agency alltransactions quarterly index is used. Furthermore, data on annual nominal per capita disposable income and population come from the Bureau of Economic Analysis. Annual population data is transfered to quarterly data using linear interpolation. Annual per capita disposable income is transfered to quarterly data using cubic spline. Applying cubic spline has the advantage that the resulting data is smooth in the first derivative. In order to get real values of house prices and per capita disposable income, the nominal values are divided by the consumer price index. Using real variables is in line with the literature on house price dynamics. However, this will not allow us to exactly compare our results to Genesove and Mayer (2001) and Engelhardt (2003) who find that loss aversion in the housing market depends on 
nominal loss. The annual consumer price index (all urban consumers) is obtained from the Bureau of Labor statistics. The regional consumer price index is not available for all MSAs used in our sample. ${ }^{4}$ Again, quarterly data are obtained by using cubic spline. Monthly unemployment rates from the Bureau of Labor Statistics are transfered to quarterly data by taking the quarterly averages. Population density is calculated using the population data mentioned above and the land area taken from the TIGER/Line shapefiles from the United States Census Bureau. Monthly new privately owned housing units authorized are taken from the United States Census Bureau. ${ }^{5}$ Quarterly data is obtained by using the sum of the monthly building permits. Building permits are divided by population. Data details can be found in Table 1.

As presented in equation 4, the quarterly growth rate of the real house price index is used in the estimation, as this time series is stationary. The explanatory variables annual growth rates of real per capita disposable income, population, and unemployment, as well as the log of building permits per population are all stationary. ${ }^{6}$ Unfortunately data for the effective mortgage interest rate is not available for all 319 MSAs (Mikhed and Zemcík, 2009). However, we include time dummies to capture changes in the fundamentals that hit all regions at the same time, like for example changes in the federal funds rate.

\section{Empirical Results}

To get an idea of the overall spatial dependence, disregarding any heterogeneity across space or time, we start with the spatial fixed effects panel estimation, where real quarterly house price growth rates are regressed on annual population growth, annual growth of the unemployment rate, annual growth of real per capita disposable

\footnotetext{
${ }^{4}$ Regional consumer price indexes are available for New York-Northern New Jersey-Long Island, NY-NJ-CT-PA; Philadelphia-Wilmington-Atlantic City, PA-NJ-DE-MD; Boston-BrocktonNashua, MA-NH-ME-CT; Pittsburgh, PA; Chicago-Gary-Kenosha, IL-IN-WI; Detroit-Ann Arbor-Flint, MI; St. Louis, MO-IL; Cleveland-Akron, OH; Minneapolis-St. Paul, MN-WI; Milwaukee-Racine, WI; Cincinnati-Hamilton, OH-KY-IN; Kansas City, MO-KS; WashingtonBaltimore, DC-MD-VA-WV; Dallas-Fort Worth, TX; Houston-Galveston-Brazoria, TX; Atlanta, GA; Miami-Fort Lauderdale, FL; Tampa-St. Petersburg-Clearwater, FL; Los Angeles-Riverside-Orange County, CA; San Francisco-Oakland-San Jose, CA; Seattle-TacomaBremerton, WA; San Diego, CA; Portland-Salem, OR-WA; Honolulu, HI; Anchorage, AK; Phoenix-Mesa, AZ and for Denver-Boulder-Greeley, CO. For the other MSAs used in our sample the following regional consumer price indexes are used: Northeast, Midwest, South, West.

${ }^{5}$ We thank Konstantin A. Kholodilin for kindly providing these data.

${ }^{6} \mathrm{We}$ do not include quarterly growth rates of the explanatory variables, even if the dependent variable is expressed in quarterly growth rates, because the quarterly data of real per capita disposable income and population is generated artificially from annual data.
} 
income, the log of building permits per population, the spatial lag of the dependent variable, and on quarterly time dummies. Because data on building permits are only available over a rather short time span, the estimation is conducted for the period 2004Q2 to 2009Q2 (Table 2). Over this time span a balanced panel is available for 319 regions. The standard errors presented are Huber-White heteroscedasticity consistent (Huber, 1967; White, 1980). Those standard errors allow for not just heteroscedasticity in the standard errors but also for autocorrelation among observations within one cluster, where clustering takes place by MSA. However, the Huber-White standard errors do not allow for correlation among observations across clusters. This could be an inappropriate constraint as, for example, different MSAs within one state are faced by the same state specific laws. One could include state dummies to capture state effects and common shocks hitting only one state, but this is not feasible, as some MSAs cross state boundaries. Therefore, for robustification, we also estimate Driscoll-Kraay standard errors, which allow for heteroscedasticity and are robust to cross-sectional and temporal dependence as the time dimension becomes large (Driscoll and Kraay, 1998). In this way we allow for unobservable common disturbances, even across MSAs. The estimated Driscoll-Kraay standard errors are similar to the Huber-White standard errors presented in Table 2. The Driscoll and Kraay (1998) standard error estimates are robust as the time dimension gets large. However, the time dimension in our estimation is only 21 . Therefore and because the Driscoll-Kraay standard errors are very similar to the Huber-White standard errors, we simply present the Huber-White standard errors. In the nonlinear estimation we proceed the same way.

With this spatial panel estimation we want to capture the spatial spillovers in house price developments, however, we cannot make the distinction between spatial spillover and common shocks that hit some MSAs instantaneously and some with a time lag. ${ }^{7}$ It could be, that a common shock hits first some regions with a very liquid housing market and reaches others with a certain time delay. Our estimation would mistake this different timing in the reaction to a common shock as spillover of house price developments. As we cannot differentiate between common shocks with region specific reaction time and spatial spillovers, we probably overestimate the coefficient of the spatially lagged dependent variable.

The results point to a strong spillover effect of neighboring house price developments. Furthermore, the estimation results reveal a positive effect of population and real per capita disposable income growth on house price growth rates. An expected negative effect of increasing unemployment rates on house price growth rates turns out not to

\footnotetext{
${ }^{7}$ Common shocks, hitting all regions at the same time are captured by the time dummy variables.
} 
Table 2: Spatial Panel Estimation

\begin{tabular}{l|l|l}
\hline \hline \multicolumn{2}{l|}{ Dependent variable: } & quarterly real house price growth rate, hpi \\
\hline Variable & FE coefficients & Huber-White standard errors \\
\hline$\alpha$ population $_{t-3}$ & $0.26^{* * *}$ & 0.10 \\
$\beta$ unemployment $_{t-2}$ & -0.003 & 0.003 \\
$\zeta$ income $_{t-2}$ & $0.14^{* * *}$ & 0.02 \\
$\delta$ building permits $_{t-1}$ & $0.003^{* * *}$ & 0.0007 \\
$\rho \mathrm{W} \times$ hpi $_{t-1}$ & $0.73^{* * *}$ & 0.04 \\
\hline$R^{2}$ & 0.61 & \\
AIC & -8.3692 & \\
Observations $_{\text {Number of groups }}$ & 6699 & \\
Time period & 319 & \\
Time dummies & yes & \\
\hline
\end{tabular}

Notes: FE estimation with robust standard errors to conditional heteroskedasticity of unknown form; ${ }^{* *},{ }^{* *},{ }^{*}$ statistically significant at one, five, and ten percent, respectively. Variables: population $=$ annual population growth, unemployment $=$ annual growth of the unemployment rate, income $=$ annual real per capita disposable income growth, building permits $=$ log building permits per population, $\mathrm{W} \times h p i=$ spatially weighted quarterly real house price growth rate of neighboring regions.

be significant. Furthermore, more building permits are associated with higher house price growth rates. This is an interesting result, as one could also assume that more building permits increase the supply of available housing and thereby reduce house prices. However, the coefficients assume the same strength of the spatial spillover or the same effect of the fundamentals no matter which region or time period we are looking at. These global effects could be misleading locally. The panel smooth transition regression model will help determine whether these coefficients hold for all regions in every single time period.

The results of the panel smooth transition regression in the case of two extreme regimes are presented in Table 3 , the corresponding transition function is plotted in Figure $3 .^{8}$ For almost all negative values of the transition variable, i.e. decreasing neighboring house prices, the transition function is equal to zero. This implies that the coefficients of the different explanatory variables are equal to $\Theta_{0}$ in case of decreasing neighboring house prices, where $\Theta_{0}=\left(\alpha_{0} \beta_{0} \zeta_{0} \delta_{0} \rho_{0}\right)$. Furthermore, the transition function is equal to one for very high growth rates of neighboring house prices of above 15 percent. For those high growth rates of neighboring house prices, the coefficients of the explanatory variables are equal to $\Theta_{0}+\Theta_{1}$. The location

\footnotetext{
${ }^{8}$ The case of three extreme regimes in analyzed in the appendix.
} 
Figure 3: Transition function vs. transition variable, two extreme regimes

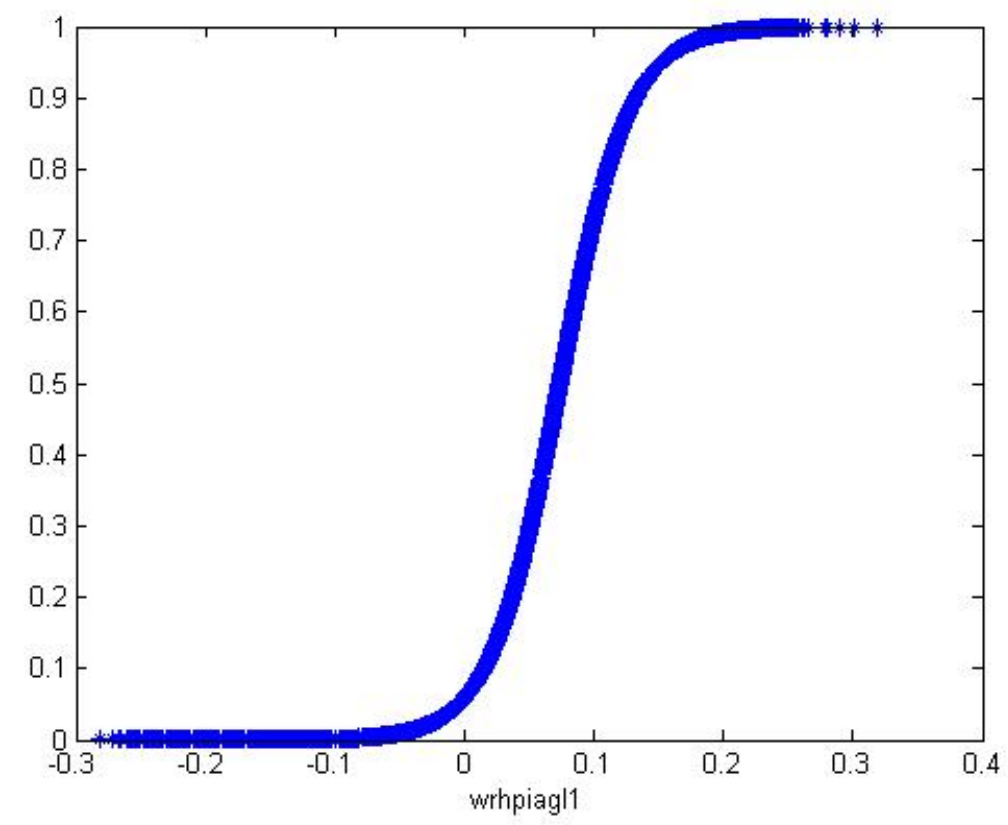

Notes: Transition variable - spatially weighted annual real house price growth rate of neighboring regions, Whpiagt-1 $_{t}$

parameter, $c$, is equal to 0.07 , which implies that when neighboring house prices grow, on average, by 7 percent, the coefficient is equal to $\Theta_{0}+0.5 \times \Theta_{1}$. The slope parameter, $\gamma$, is equal to 37.49. In the literature such a value is not assumed to imply an instantaneous transition between regimes but a relatively smooth transition (Trupkin and Ibarra, 2011; Lee and Chien, 2011).

Most interestingly, the coefficient of the spatially lagged dependent variable is much smaller in case of decreasing neighboring house prices, $\rho_{0}=0.33$, than in case of strongly increasing neighboring house prices, $\rho_{0}+\rho_{1}=0.6$. That means that house price developments in neighboring regions spill over more in times of increasing neighboring house prices than during times of declining neighboring house prices. This is interpreted as evidence for the disposition effect, i.e. home owners do not sell their houses even if they get the signal of declining house prices from neighboring regions. Thus, our results confirm the findings by Genesove and Mayer (2001) and Engelhardt (2003) of loss aversion. However, the authors find only nominal and not real loss aversion as we do. As mentioned in the introduction, homeowners tend to avoid new information regarding neighboring house price declines or find explanations as to why neighboring house price decreases will not spill over into their region. This behavior indeed leads to smaller spillover effects in times of decreasing 
neighboring house prices.

Overall, we find evidence for heterogeneity in spatial spillovers of house price developments across space and time. This confirms and augments the findings by Gray (2012) of heterogeneity in house price spillovers across space.

Figure 4 is a plot of the individual coefficients of the spatially lagged dependent variable for four points in time and reveals the amount of heterogeneity across time and space in spatial house price spillovers. The plotted coefficients vary between $\rho_{0}=0.33$, implying weak spatial spillovers of house price developments, and $\rho_{0}+\rho_{1}=0.60$, implying strong spatial spillovers of house price developments. Those strong spillovers are especially observed for the coastal regions for example in 2004Q2, or 2005Q3. The house price spillovers in the inland at that time are more at the lower bound of 0.33 . When house prices started to decline at the end of 2006, the spillovers quickly declined in the coastal regions and reached for almost all regions the lower bound of 0.33 in 2008Q1. Moreover, 4192 out of 6699 observations overall (319 regions over 21 time periods) have coefficients between 0.4 and 0.5 , as compared to the extreme regime coefficients $\rho_{0}=0.33$ and $\rho_{0}+\rho_{1}=0.6$. Thus, assuming only two extreme regimes without smooth transition between them would not be appropriate for more than 60 percent of all observations.

The estimation results further reveal that there is no heterogeneity in the effect of real per capita disposable income on house price developments, as the test statistic reveals no significant difference between the coefficients $\zeta_{0}$ and $\zeta_{0}+\zeta_{1}$. The coefficient on the unemployment rate is significant negative in one extreme regime and significant positive in the other extreme regime. The coefficients between $\beta_{0}$ and $\beta_{0}+\beta_{1}$ are close to zero and probably insignificant, as in the spatial panel regressions. Therefore we do not worry about the unreasonable positive effect of the unemployment rate in times of very high house price growth rates. Moreover, the coefficient of population growth is insignificant in times of decreasing neighboring house prices and becomes significant when neighboring house prices increase. This result implies that, compared to the strong increases, the strong decline in house prices in the sample period could less be explained by fundamentals. In sum, heterogeneity in the effect of the fundamentals on house price dynamics could not be detected for all variables; real per capita disposable income and the unemployment rate have a homogeneous effect across time and space.

The test of no remaining non-linearity proposed by González et al. (2005) confirms that the linear model presented in Table 2 is not appropriate. Furthermore, the $R^{2}$ and the Akaike information criteria confirm an improvement of the non-linear model over the linear model. However, test results reveal that there is still non-linearity 
Table 3: PSTR Estimation results, two extreme regimes

\begin{tabular}{l|l|l|l}
\hline \hline \multicolumn{3}{l|}{ Dependent variable: quarterly real house price growth rate, hpi } \\
\hline Variable & Coefficients & $\begin{array}{l}\text { Huber-White } \\
\text { t-statistic }\end{array}$ & $\begin{array}{l}\text { Difference between } \\
\text { Coefficients }\end{array}$ \\
\hline$\alpha_{0}$ population $_{t-3}$ & 0.07 & 1.43 & \\
$\beta_{0}$ unemployment $_{t-2}$ & $-0.02^{* * *}$ & -11.34 & \\
$\zeta_{0}$ income $_{t-2}$ & $0.13^{* * *}$ & 7.46 & \\
$\delta_{0}$ building permits $_{t-1}$ & $0.005^{* * *}$ & 9.41 & \\
$\rho_{0} \mathrm{~W} \times$ hpi $_{t-1}$ & $0.33^{* * *}$ & 9.39 & \\
& & & $-5.73^{* * *}$ \\
$\alpha_{0}+\alpha_{1}$ population $_{t-3}$ & $0.50^{* * *}$ & 8.60 & $-11.41^{* * *}$ \\
$\beta_{0}+\beta_{1}$ unemployment $_{t-2}$ & $0.05^{* * *}$ & 9.95 & -1.40 \\
$\zeta_{0}+\zeta_{1}$ income $_{t-2}$ & $0.18^{* * *}$ & 5.36 & $3.97^{* * *}$ \\
$\delta_{0}+\delta_{1}$ building permits $_{t-1}$ & $0.002^{* * *}$ & 3.76 & $-5.44^{* * *}$ \\
$\rho_{0}+\rho_{1} \mathrm{~W}_{\times \text {hpi }}{ }_{t-1}$ & $0.60^{* * *}$ & 17.37 & \\
\hline$\gamma$, slope & 37.49 & & \\
$c$, location parameter & 0.07 & & \\
$R^{2}$ & 0.63 & & \\
AIC & -8.3949 & & \\
Observations & 6699 & & \\
Number of groups & 319 & & \\
Time period & $2004 \mathrm{Q} 2-2009 \mathrm{Q} 2$ & & \\
Time dummies & yes & & \\
\hline \hline
\end{tabular}

Notes: FE estimation with robust standard errors to conditional heteroskedasticity of unknown form; ${ }^{* * *}, * *, *$ statistically significant at one, five, and ten percent, respectively. Variables: population $=$ annual population growth, unemployment $=$ annual growth of the unemployment rate, income $=$ annual real per capita disposable income growth, building permits $=\log$ building permits per population, $\mathrm{W} \times h p i=$ spatially weighted quarterly real house price growth rate of neighboring regions. 
Figure 4: Individual spatial spillover parameters at different points in time, two extreme regimes

2004 Q2

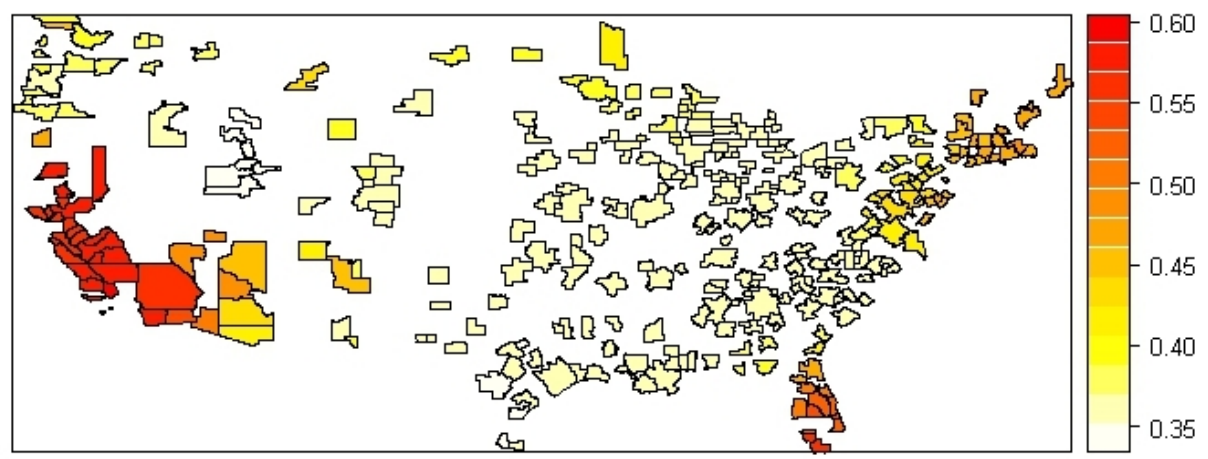

2005 Q3

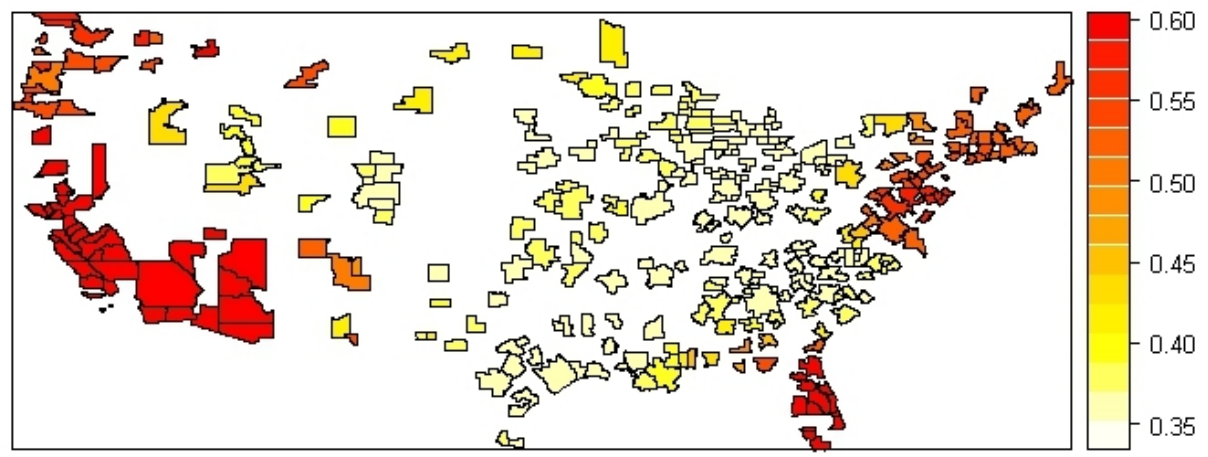

2006 Q4
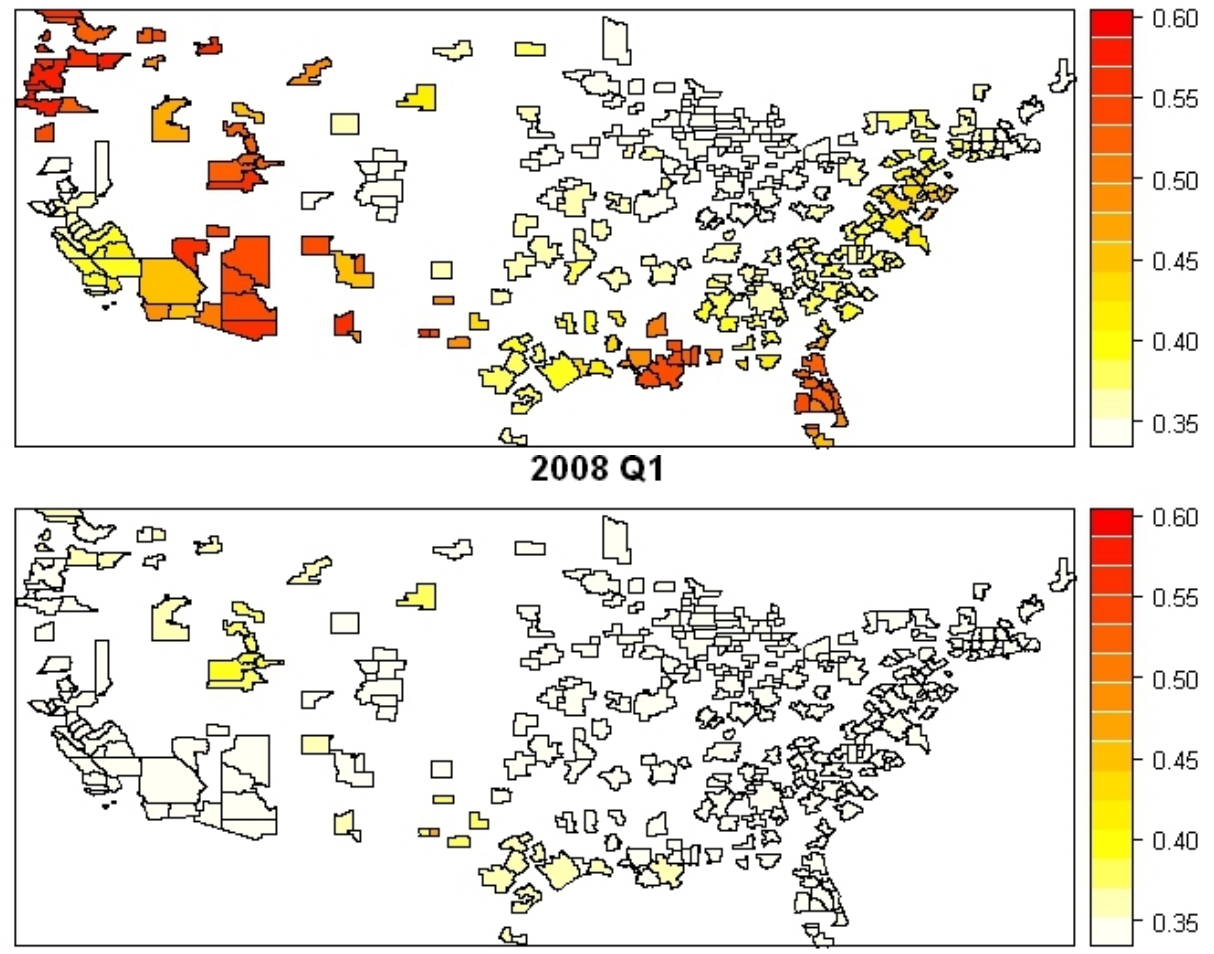

Notes: Individual spatial spillover parameters vary between $\rho_{0}=0.33$ and $\rho_{0}+\rho_{1}=0.60$. 
in the non-linear model with two extreme regimes and also in the model with three extreme regimes. González et al. (2005) argue that heteroskedasticity may lead to a higher test statistic and thus to reject the null hypothesis of no remaining nonlinearity more often. We conclude that, even if there is room for improvement, the PSTR model with two extreme regimes is a first step to model non-linearities, and thus, to better understand regional house price dynamics.

\section{Conclusion}

This paper is a joint analysis of three spatial characteristics in house price dynamics, namely spatial dependence, spatial heterogeneity, and heterogeneity in spatial dependence. While spatial dependence and spatial heterogeneity are well established aspects of house price developments, heterogeneity in spatial dependence has not gained much attention yet. We argue that the disposition effect may explain different house price spillovers across space and time. Assuming incorrectly homogeneous spillovers could locally give a misleading picture of house price dynamics.

First, a spatial panel regression is estimated to see whether there is overall spatial dependence in house price developments. Subsequently, a panel smooth transition regression model is applied to estimate the heterogeneity across space and time in spatial dependence and in the effect of the fundamentals on house price dynamics. To the best of our knowledge, this paper is the first applying this nonlinear model to jointly analyze the three aspects of spatial data, the first paper which explicitly models heterogeneity in spatial dependence, and the first paper which tries to model the disposition effect using heterogeneity in spatial spillovers.

The results reveal strong house price spillovers when the average annual house price increase of the neighboring regions is greater than 15 percent. Significant lower house price spillovers are detected for times of declining house prices in the neighboring regions. This is seen as evidence for the disposition effect, i.e. that people hold on their losing assets even if they get strong signals of declining house prices from the neighboring regions. Thus our results confirm previous findings by Genesove and Mayer (2001) and Engelhardt (2003) of loss aversion in the housing market. Heterogeneity in the effect of the fundamentals on house price dynamics is only found for population growth and building permits, but not for real per capita disposable income and the unemployment rate. The detected heterogeneity in the effect of population growth on house price developments suggest that fundamentals serve 
less explaining the house price developments in times of declining house prices compared to strongly increasing house prices.

This analysis shows that it is not appropriate to assume uniform house price spillovers across space and time. In times of declining house prices the spillovers are much lower than what the linear estimation suggests. The panel smooth transition regression model is an appropriate tool to model those nonlinearities in spatial spillovers across time and space.

\section{Appendix}

Because of theoretical consideration and the fact that the estimation is conducted over a relative short time span of 21 quarters, we assumed that there are only two extreme regimes. However, Figure 2, which is a plot of our transition variable, the spatially weighted annual growth rate of neighboring house prices, Whpiag t $_{t-1}$, shows that in the sample there are very high annual growth rates of above 20 percent and very low growth rates of below minus 20 percent. This could imply that there are three regimes, one for very high growth rates of the transition variable, one for strong negative growth rates of the transition variable, and one for growth rates in between. That is why we also estimate the PSTR model for the case of three extreme regimes. For the case of three extreme regimes, the logistic transition function is given by:

$$
g\left(q_{\mathrm{it}} ; \gamma, c\right)=\frac{1}{1+e^{-\gamma\left(q_{\mathrm{it}}-c_{1}\right)\left(q_{\mathrm{it}}-c_{2}\right)}},
$$

where $c=\left(c_{1}, c_{2}\right)$ is the vector of location parameters. If the transition variable, $q_{\mathrm{it}}$, is smaller than the first location parameter, $c_{1}$, the transition function, $g\left(q_{\mathrm{it}} ; \gamma, c\right)$, tends to one, and the coefficients tend to $\theta_{0}+\theta_{1}$. If the transition variable, $q_{\mathrm{it}}$, is larger than the location parameter, $c_{2}$, the transition function, $g\left(q_{\mathrm{it}} ; \gamma, c\right)$, tends again to one, and the coefficients tend to $\theta_{0}+\theta_{1}$. If the transition variable, $q_{i t}$, is larger than the first location parameter, $c_{1}$, and smaller than the second location parameter, $c_{2}$, the transition function, $g\left(q_{\mathrm{it}} ; \gamma, c\right)$, tends to zero, and the coefficients tend to $\theta_{0}$.

The corresponding transition function for the case of three extreme regimes is plotted in Figure 5. It appears that the assumption of three extreme regimes is not appropriate. The transition function is similar to the transition function in case of two extreme regimes between 20 percent decrease and 30 percent increase in neighboring house prices. Between 30 and 20 percent decrease there is a smooth 
Figure 5: Transition function vs. transition variable, three extreme regimes

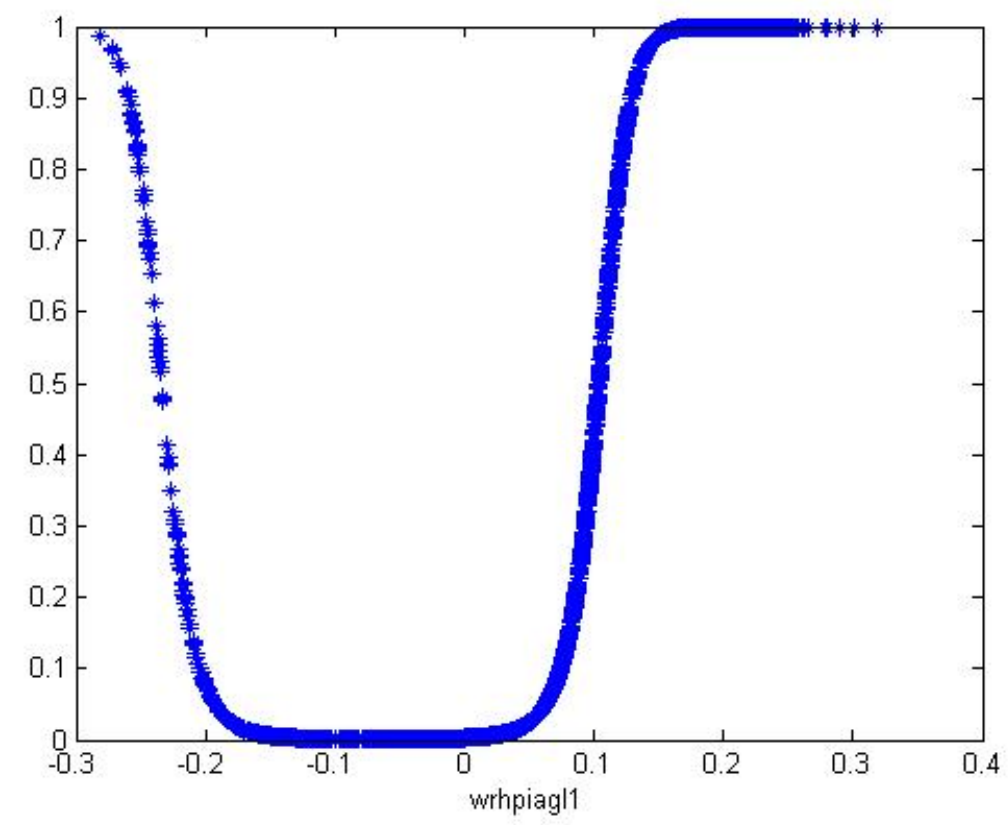

Notes: Transition variable - spatially weighted annual real house price growth rate of neighboring regions, Whpiagt-1 $_{t}$

transition of the transition function from 1 to 0 , however, there are no observations in the extreme regime of strongly declining house prices. Thus it appears to be appropriate to stick to the estimation results presented in Table 3. However, the results for three regimes are similar to the results presented in Table 3 and will be provided upon request. 


\section{References}

Anselin, L., 1988. Spatial Econometrics: Methods and Models. Kluwer Academic Publishers.

Anselin, L., Gallo, J., Jayet, H., 2008. Spatial Panel Econometrics. In: Mátyás, L., Sevestre, P. (Eds.), The Econometrics of Panel Data. Vol. 46 of Advanced Studies in Theoretical and Applied Econometrics. Springer Berlin Heidelberg, pp. 625-660.

Brady, R. R., 2011. Measuring the diffusion of housing prices across space and over time. Journal of Applied Econometrics 26 (2), 213-231.

de Bandt, O., Barhoumi, K., Bruneau, C., 2010. The International Transmission of House Price Shocks. In: Bandt, O., Knetsch, T., Penalosa, J., Zollino, F. (Eds.), Housing Markets in Europe. Springer Berlin Heidelberg, pp. 129-158.

de Bandt, O., Malik, S., 2010. Is there Evidence of Shift-Contagion in International Housing Markets? Banque de France Working Paper 295, Banque de France.

Dieleman, F. M., Clark, W. A. V., Deurloo, M. C., 2000. The Geography of Residential Turnover in Twenty-seven Large US Metropolitan Housing Markets, 1985-95. Urban Studies 37 (2), 223-245.

Driscoll, J. C., Kraay, A. C., 1998. Consistent Covariance Matrix Estimation With Spatially Dependent Panel Data. The Review of Economics and Statistics 80 (4), $549-560$.

Engelhardt, G. V., 2003. Nominal loss aversion, housing equity constraints, and household mobility: evidence from the united states. Journal of Urban Economics $53(1), 171-195$.

Federal Register, June 2010. 2010 Standards for Delineating Metropolitan and Micropolitan Statistical Areas. Federal Register 75 (123), 37246-37252.

Festinger, L., 1957. A Theory of Cognitive Dissonance. Stanford University Press, Stanford, CA.

Genesove, D., Mayer, C., 2001. Loss Aversion and Seller Behavior: Evidence from the Housing Market. The Quarterly Journal of Economics 116 (4), 1233-1260.

Giussani, B., Hadjimatheou, G., 1991. Modeling Regional House Prices in the United Kingdom. Papers in Regional Science 70 (2), 201-219. 
González, A., Teräsvirta, T., van Dijk, D., 2005. Panel Smooth Transition Regression Models. Working Paper Series in Economics and Finance 604, Stockholm School of Economics.

Gray, D., 2012. District House Price Movements in England and Wales 1997-2007: An Exploratory Spatial Data Analysis Approach. Urban Studies 49 (7), 14111434.

Holly, S., Hashem Pesaran, M., Yamagata, T., 2011. The spatial and temporal diffusion of house prices in the UK. Journal of Urban Economics 69 (1), 2-23.

Huber, P. J., 1967. The behavior of maximum likelihood estimates under nonstandard conditions. Proceedings of the 5th Berkeley Symposium on Mathematical Statistics and Probability, 221-233.

Kahneman, D., Tversky, A., 1979. Prospect Theory: An Analysis of Decision under Risk. Econometrica 47 (2), 263-291.

Kodres, L. E., Pritsker, M., 2002. A Rational Expectations Model of Financial Contagion. The Journal of Finance 57 (2), 769-799.

Kosfeld, R., 2006. Regional Spillovers and Spatial Heterogeneity in Matching Workers and Employers in Germany. Discussion Papers in Economics 89/06, University of Kassel, Institute of Economics.

Kuethe, T., Pede, V., 2011. Regional Housing Price Cycles: A Spatio-temporal Analysis Using US State-level Data. Regional Studies: The Journal of the Regional Studies Association 45 (5), 563-574.

Lee, C.-C., Chien, M.-S., 2011. Empirical Modelling of Regional House Prices and the Ripple Effect. Urban Studies 48 (10), 2029-2047.

Lee, L.-f., Yu, J., 2010. Some recent developments in spatial panel data models. Regional Science and Urban Economics 40 (5), 255-271.

Meen, G., 1999. Regional House Prices and the Ripple Effect: A New Interpretation. Housing Studies 14 (6), 733-753.

Mikhed, V., Zemcík, P., 2009. Do house prices reflect fundamentals? Aggregate and panel data evidence. Journal of Housing Economics 18 (2), 140-149.

Molloy, R., Smith, C. L., Wozniak, A. K., 2011. Internal Migration in the United States. NBER Working Paper 17307, National Bureau of Economic Research. 
Shefrin, H., Statman, M., 1985. The Disposition to Sell Winners Too Early and Ride Losers Too Long: Theory and Evidence. The Journal of Finance 40 (3), 777-790.

Shiller, R. J., 1999. Human behavior and the efficiency of the financial system. In: Taylor, J. B., Woodford, M. (Eds.), Handbook of Macroeconomics. Vol. 1 of Handbook of Macroeconomics. Elsevier, Ch. 20, pp. 1305-1340.

Terasvirta, T., 1994. Specification, Estimation, and Evaluation of Smooth Transition Autoregressive Models. Journal of the American Statistical Association 89 (425), 208-218.

Thaler, R. H., 1999. Mental Accounting Matters. Journal of Behavioral Decision Making 12 (3), 183-206.

Trupkin, D., Ibarra, R., 2011. The Relationship between Inflation and Growth: A Panel Smooth Transition Regression Approach for Developed and Developing Countries. Documentos de Trabajo/Working Papers 1107, Facultad de Ciencias Empresariales y Economia. Universidad de Montevideo.

van Dijk, B., Franses, P. H., Paap, R., van Dijk, D., 2011. Modelling regional house prices. Applied Economics 43 (17), 2097-2110.

White, H., 1980. A Heteroskedasticity-Consistent Covariance Matrix Estimator and a Direct Test for Heteroskedasticity. Econometrica 48 (4), 817-838.

Wood, R., 2003. The Information Content of Regional House Prices: Can they be used to Improve National House Price Forecasts? Bank of England Quarterly Bulletin Autum, 304-314. 